\title{
Up-Regulation of Trypsin and Mesenchymal MMP-8 During Development of Hyperoxic Lung Injury in the Rat
}

\author{
KATARIINA CEDERQVIST, JOAKIM JANER, TAINA TERVAHARTIALA, TIMO SORSA, CAJ HAGLUND, KAISA SALMENKIVI, \\ ULF-HÅKAN STENMAN, AND STURE ANDERSSON
}

\author{
Departments of Pediatrics [K.C., J.J., S.A.], Oral and Maxillofacial Diseases [T.T., T.S.], Surgery [C.H.], Pathology [K.S.], and Clinical \\ Chemistry [U-H.S.], Helsinki University Central Hospital and University of Helsinki, FIN-00290 Helsinki, Finland
}

\begin{abstract}
Acute lung injury is marked by damage to alveolarcapillary barrier. High pulmonary levels of matrix-degrading serine proteinase trypsin and matrix metalloproteinases (MMP)-2, -8, and -9 have been shown in preterm infants with respiratory distress syndrome (RDS). We studied expression of trypsin and MMP-2, -8, and -9 in rats exposed to $>95 \%$ oxygen for 24,48 , or $60 \mathrm{~h}$. As demonstrated by zymography and Western immunoblotting, levels of trypsin and MMP-2, -8 , and -9 in bronchoalveolar lavage fluid (BALF) sharply increased after $48 \mathrm{~h}$ of hyperoxia relative to normoxia controls. This coincided with increase in alveolar-capillary permeability, as indicated by increased protein concentration in BALF. Both neutrophil-derived $80-\mathrm{kD}$ and mesenchymal cellderived 60-kD MMP-8 isoforms were detected in BALF. Of them, mesenchymal-type MMP-8 predominated. In immunohistochemistry, alveolar epithelium showed strong trypsin expression at 48 and $60 \mathrm{~h}$ of hyperoxia, whereas it was predominantly negative in controls. MMP-8 was mostly expressed in macrophages. Marked upregulation of trypsin and MMP-8 early during hyperoxic lung injury suggests that these enzymes play a role in the pathogenesis of acute lung injury and may therefore be potential targets for therapy of lung injury. (Pediatr Res 60: 395-400, 2006)
\end{abstract}

$\mathrm{T}$ he extracellular matrix (ECM) between epithelial and capillary endothelial layers and in particular the basement membranes $(\mathrm{BM})$ of the cell layers are essential in the maintenance of the structural and functional integrity of the alveolar wall (1). Trypsin is a serine proteinase that can efficiently degrade various ECM proteins; at very low concentrations, it is capable of activating proforms of several MMPs, thus having potential to initiate a broad-spectrum proteinase cascade eventually leading to tissue destruction (2,3). Multiple isoforms of trypsin have been demonstrated in human pancreas and in most animal species $(4,5)$. Trypsinogen- 1 and -2 were detected for the first time outside the gastrointestinal tract in cyst fluid of human ovarian tumors (6). Later, trypsinogens have been identified in a variety of human extrapancreatic tissues including normal human epithelial cells of the

Received February 1, 2006; accepted May 22, 2006.

Correspondence: Katariina Cederqvist, M.D., Hospital for Children and Adolescents, Research Laboratory, Biomedicum Helsinki, P.O. Box 700, FIN-00290 Helsinki, Finland; e-mail: katariina.cederqvist@helsinki.fi

This research was supported by grants from the Foundation for the Pediatric Research, Finska Läkeresällskapet, The Sigrid Jusélius Foundation, the Academy of Finland, and the Helsinki University Central Hospital Research Fund.

DOI: 10.1203/01.pdr.0000238342.16081.f9 lung, vascular endothelial cells, and various cancers $(4,7,8)$. Recently, ectopic trypsin was identified in rat lung (9).

In the lung, trypsin may induce tissue injury not only through initiating matrix-degrading proteolytic cascade, but also through proinflammatory actions. Trypsin is a potent activator of proteinase-activated receptor $2\left(\mathrm{PAR}_{2}\right)$, a $\mathrm{G}$ protein-coupled receptor that is believed to play an important role in airway inflammation $(10,11)$. In preterm infants, high pulmonary trypsinogen-2 early postnatally is associated with the severity of acute lung injury and with the development of bronchopulmonary dysplasia (BPD) (8). Furthermore, in autopsy specimens from preterm infants who died of respiratory distress syndrome (RDS) or BPD, trypsin-2 colocalizes with $\mathrm{PAR}_{2}$ in alveolar and bronchial epithelium (12).

MMPs are a family of zinc-dependent, genetically distinct but structurally related endopeptidases collectively capable of degrading almost all components of ECM. MMP-2 and MMP-9 are type IV collagenases that can disrupt alveolar BM (13). MMP-8 belongs to the collagenase subfamily of MMPs and cleaves collagen types I-III, of which I and III are the major structural components of the pulmonary interstitial ECM. Furthermore, MMP-8 can act on various nonmatrix proteins such as serine proteinase inhibitors (serpins) and chemokines and thus may modulate inflammatory processes in different ways $(14,15)$. Increased levels of MMP-2, MMP-8, and MMP-9 are associated with inflammatory lung diseases such as RDS, BPD, and asthma (13,16-18).

Hyperoxia-induced lung injury (exposure to $>95 \%$ oxygen), a well-established model of acute lung injury, is characterized by damage to the alveolar-capillary barrier with subsequent increased pulmonary vascular permeability, progressive inflammation, and pulmonary edema (19). In rats exposed to $100 \%$ oxygen, the first signs of increased alveolarcapillary permeability are detected at $48 \mathrm{~h} \mathrm{(20).} \mathrm{Severe} \mathrm{inter-}$ stitial and alveolar edema is present at $60 \mathrm{~h}$, leading to death usually within $72 \mathrm{~h}$ of exposure $(19,20)$.

Abbreviations: BALF, bronchoalveolar lavage fluid; BM, basement membrane; BPD, bronchopulmonary dysplasia; ECM, extracellular matrix; MMP, matrix metalloproteinase; MPO, myeloperoxidase; $\mathbf{P A R _ { 2 }}$, proteinase-activated receptor 2; RDS, respiratory distress syndrome 
Association of high pulmonary levels of trypsin, MMP-2, -8 , and -9 with tissue-destructive lung diseases suggests that these proteinases may play an important role in the pathogenesis of lung injury. By use of an experimental animal model, we wanted to determine the cellular localization and chronological increase of these proteinases during development of acute lung injury. Therefore, we characterized trypsin, MMP-2, -8 , and -9 in lungs of rats exposed to $>95 \%$ oxygen for 24,48 , and $60 \mathrm{~h}$.

\section{METHODS}

Experimental model. The study protocol was approved by the Institutional Review Board for Animal Studies of Helsinki University Central Hospital, Helsinki, Finland. Female Wistar rats (Harlan Nederland, Horst, The Netherlands) aged $8 \mathrm{wk}$ were housed for $1 \mathrm{wk}$ before use. The animals were placed in a sealed Plexiglas chamber $(85 \times 60 \times 40 \mathrm{~cm})$ and exposed to $>95 \% \mathrm{O}_{2}$ for $24 \mathrm{~h}(n=6), 48 \mathrm{~h}(n=6)$, and $60 \mathrm{~h}(n=6)$ by administration of pure oxygen at $5 \mathrm{~L} / \mathrm{min} . \mathrm{O}_{2}$ concentration was monitored with an oximeter (Datex, Helsinki, Finland). Food and water were allowed ad libitum and a 12-/12-h light/dark cycle was maintained. Control animals $(n=6)$ were kept in room air. At different exposure times, animals were anesthetized by intraperitoneal injections of ketamine $(50 \mathrm{mg} / \mathrm{kg})$ and xylazine $(10 \mathrm{mg} / \mathrm{kg})$ and killed by cervical dislocation. Immediately after decapitation, the right lung was removed and cut into two pieces. The pieces were soaked in isotonic saline, snap frozen in liquid nitrogen, and stored at $-80^{\circ} \mathrm{C}$ until determination of myeloperoxidase (MPO) activity. The left lung was removed, fixed in $10 \%$ paraformaldehyde for $24 \mathrm{~h}$, embedded in paraffin, and stored at room temperature for subsequent immunohistochemistry.

Bronchoalveolar lavage (BAL). In a parallel experiment, BAL was performed for normoxia controls $(n=8)$ and rats exposed to $>95 \% \mathrm{O}_{2}$ for $24 \mathrm{~h}$ $(n=8), 48 \mathrm{~h}(n=8)$, and $60 \mathrm{~h}(n=8)$. Immediately after killing the rat, the trachea was cannulated, and the lungs were lavaged by flushing with sterile isotonic saline $(10 \mathrm{~mL})$ as 10 aliquots of $1 \mathrm{~mL}$ each. BALF samples were kept on ice until centrifuged at $500 \times g$ for $10 \mathrm{~min}$ at $4{ }^{\circ} \mathrm{C}$, and the supernatant was stored at $-20^{\circ} \mathrm{C}$ for subsequent analyses. Protein concentration in BALF was measured (21) and used as an indicator of increased vascular permeability and loss of capillary endothelial membrane integrity.

Gelatin zymography. For analysis of gelatinolytic activity by zymography, BALF samples were run on $1.5-\mathrm{mm}$ thick $8 \%-10 \%$ sodium dodecylsulfate (SDS)-polyacrylamide gels impregnated with $1 \mathrm{mg} / \mathrm{mL}$ gelatin labeled fluorescently with 2-methoxy-2,4-diphenyl-3(2H)-furanone (Fluka, Sigma Chemical Co--Aldrich, Buchs SG, Switzerland) as described previously (8). The intensities of gelatinolytic bands were evaluated with Bio-Rad Model GS-700 Imaging Densitometer using Quantity Program, new version of the Molecular Analyst/PC program (Bio-Rad Laboratories, Hercules, CA) (16). Results were expressed as arbitrary units (AU).

ECL Western blotting. In BALF, molecular weight forms of trypsin and MMP-2, -8 , and -9 were analyzed by ECL Western immunoblot method using specific antisera as described previously (16). Briefly, the BALF samples were separated on $10 \%$ SDS-polyacrylamide gels and transferred onto nitrocellulose membranes (Schleider \& Schuell, Dassel, Germany). Nonspecific binding was blocked with 5\% milk powder (Valio, Helsinki, Finland). The membranes were incubated with a 1:500 solution of polyclonal antibodies against human MMP-2 (2), MMP-8 (16), MMP-9 (2), and trypsin (1:500, Chemicon International, Temecula, CA) for $12 \mathrm{~h}$ at room temperature, and then with horseradish peroxidase-linked anti-rabbit antibody for $1 \mathrm{~h}$. The proteins were detected by the ECL detection system according to the manufacturer's instructions (Amersham Pharmacia Biotech). The intensities of immunoreacted forms of MMP-8 were evaluated and expressed as arbitrary units as described above (16).

MPO activity. MPO activity was measured as a marker of pulmonary neutrophil accumulation, as previously described (22). Briefly, lung samples were thawed and homogenized in phosphate-buffered saline (PBS). After centrifugation, the pellet was resuspended in $1 \mathrm{~mL}$ of $50 \mathrm{mmol} / \mathrm{L}$ potassium phosphate containing $0.5 \mathrm{~g} / 100 \mathrm{~mL}$ centrimonium bromide. Resuspended pellets were frozen at $-70^{\circ} \mathrm{C}$ until the MPO assay was performed. Frozen samples were thawed, sonicated for $90 \mathrm{~s}$, incubated in a $60^{\circ} \mathrm{C}$ water bath for $2 \mathrm{~h}$. After centrifugation, $33 \mu \mathrm{L}$ of supernatant was combined with $957 \mu \mathrm{L}$ of $50 \mathrm{mmol} / \mathrm{L}$ potassium phosphate buffer, $\mathrm{pH} 6.0$, containing $0.167 \mathrm{mg} / \mathrm{mL}$ $o$-dianisidine dihydrochloride and $5 \times 10^{-4} \mathrm{M}$ hydrogen peroxide. Change in absorbance was measured in a Lambda Bio UV/VIS Spectrometer (Perkin Elmer, Boston, MA) at $460 \mathrm{~nm}$ absorbance. MPO activity was expressed as
$\mathrm{mU} / \mathrm{mg}$ protein. Protein concentration was quantified by the method of Bradford (21)

Immunohistochemistry. In lung tissue, trypsin immunoreactivity was visualized with monoclonal anti-trypsin antibody, MAB 1482 (Chemicon International), and MMP-8 immunoreactivity with rabbit polyclonal antibody against human MMP-8 (23). Four-micrometer sections were deparaffinized and rehydrated. To enhance antigen retrieval, sections were pretreated with microwave heat. The sections were then treated with $0.5 \%$ hydrogen peroxide in methanol for $30 \mathrm{~min}$ and blocked with either normal horse serum (trypsin) or normal goat serum (MMP-8) (both 1:20) for $15 \mathrm{~min}$. Primary antibody to trypsin (diluted 1:1000) or to MMP-8 (diluted 1:250) was added, and the sections were incubated overnight at room temperature. Bound antibody was visualized by the avidin-biotin complex immunoperoxidase technique (ABC) (Elite ABC Kit, Vectastain, Vector Laboratories, Burlingame, CA) following the manufacturer's instructions. The sections were incubated with the biotinylated second layer antibody and the peroxidase-labeled avidin-biotin complex for $30 \mathrm{~min}$ each. Peroxidase activity was developed with 3-amino-9ethyl-carbazole (A-5754, Sigma Chemical Co.), and finally the sections were stained with hematoxylin. Sections that were treated with PBS served as negative controls. Rat pancreatic and skin specimens were used as positive controls for trypsin and MMP-8 immunohistochemistry (24).

The immunoreactivities of trypsin and MMP- 8 were analyzed independently by two investigators (K.S. and K.C.) in a blinded fashion. In each case, the entire section of lung tissue (approximately $1 \mathrm{~cm}^{2}$ ) was evaluated. The level of trypsin immunoreactivity was scored in a semiquantitative manner according to the following method: absent $=0$, low $=1$, moderate $=2$, or strong $=3$. Separate scores were given for bronchial and bronchiolar epithelium, alveolar epithelium, and vascular smooth muscle.

Statistical analysis. Data are expressed as box and whisker plots, representing median, interquartile range, and 10th and 90th percentiles. Comparisons between controls and hyperoxia groups were performed with the nonparametric multiple comparison Kruskal-Wallis test (StatView 5.0.1, Abacus Concepts Inc., Berkeley, CA). The Dunn's test was used for the post hoc comparisons. $p$ Values $<0.05$ were considered statistically significant.

\section{RESULTS}

No evident signs of respiratory distress or macroanatomic changes could be detected up to $48 \mathrm{~h}$ of exposure to $>95 \% \mathrm{O}_{2}$. At $60 \mathrm{~h}$, pleural effusions were found on opening the thoracic cavity and the lungs looked hemorrhagic and consolidated. Protein concentration in BALF was stable until $48 \mathrm{~h}$, when it was significantly increased, and after $60 \mathrm{~h}$ of exposure a 10 -fold increase was detected as compared with controls (Fig. 1A). Increased MPO activity in lung tissue was first observed at $48 \mathrm{~h}$, and the MPO activity further increased by $60 \mathrm{~h}$ (Fig. 1B).

Characterization of trypsin and MMPs in BALF. In gelatin zymograms, three gelatinolytic proteinases of molecular weights 28,68 , and $90 \mathrm{kD}$ were clearly detected at $48 \mathrm{~h}$ of
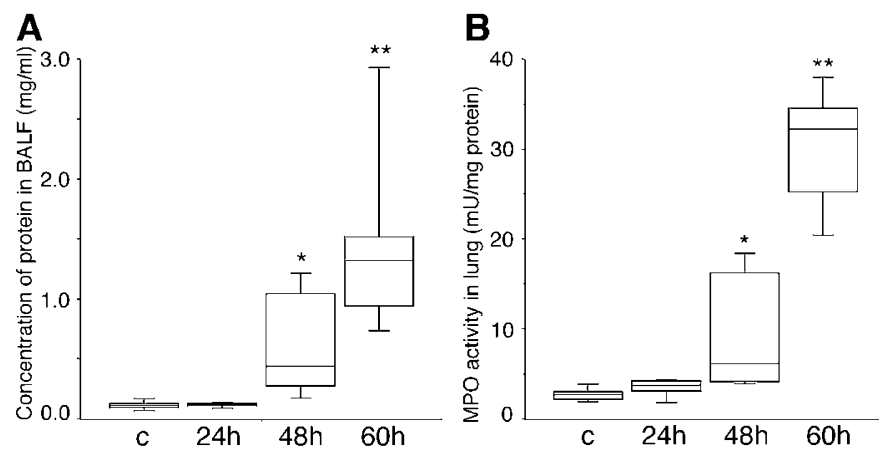

Figure 1. Protein concentration in BALF samples $(n=8$ per group) $(A)$ and MPO activity in lung homogenates $(n=6$ per group) $(B)$ from controls and rats exposed to $>95 \%$ oxygen for 24,48 , and $60 \mathrm{~h}$. Data shown as box and whisker plots, representing median, interquartile range, and 10th and 90th percentiles. $* p<0.05 ; * * p<0.0005$ vs controls. 
exposure, and the gelatinolytic activity was further increased at $60 \mathrm{~h}$ (Fig. 2A). In contrast, very faint gelatinolytic activity was detected in BALF samples from controls or rats exposed to $24 \mathrm{~h}$ of hyperoxia (Fig. 2A). By ECL Western blotting, the $28-\mathrm{kD}$ species was identified as trypsin (Fig. $2 B$ ), and the 68and $90-\mathrm{kD}$ species as proenzyme forms of MMP-2 and -9 , respectively (data not shown). At 48 and $60 \mathrm{~h}$ of exposure, Western blot analysis of BALF samples with anti-MMP-8 revealed the presence of both neutrophil-derived $80-\mathrm{kD}$ MMP-8 and 60-kD mesenchymal cell-derived MMP-8 species, of which the 60-kD mesenchymal cell-derived MMP-8 species predominated. No MMP-8 immunoreactivity could be demonstrated in controls or in rats exposed to $24 \mathrm{~h}$ of hyperoxia (Fig. 2C). Densitometric analysis demonstrated that BALF levels of trypsin and MMP-2 were significantly increased by $48 \mathrm{~h}$ of hyperoxia (Fig. 3A,B). At $60 \mathrm{~h}$, the levels of these enzymes were further increased, and a significant increase was also detected in levels of MMP-9 (Fig. 3), as well as in levels of both neutrophil-derived and mesenchymal cell-derived MMP-8 (Fig. 4).

Trypsin immunohistochemistry. In normoxia controls, low trypsin immunoreactivity was detected in bronchial and bronchiolar epithelial cells, whereas alveolar epithelium was predominantly negative (Fig. 5A). After $24 \mathrm{~h}$ of hyperoxia, there was a tendency for increased trypsin immunoreactivity in bronchial and bronchiolar epithelium when compared with controls (Figs. $5 B$ and $6 B$ ). At 48 and $60 \mathrm{~h}$, immunohistochemistry revealed moderate to strong expression of trypsin in alveolar epithelium, whereas in bronchial and bronchiolar epithelium, the trypsin level remained low (Fig. 5C and $D$ ). When compared with controls, semiquantitative scoring showed a significant increase in the level of trypsin immunoreactivity in alveolar epithelium of rats exposed to 48 and $60 \mathrm{~h}$ of hyperoxia $(p<0.05$ and $p<0.005$, respectively)
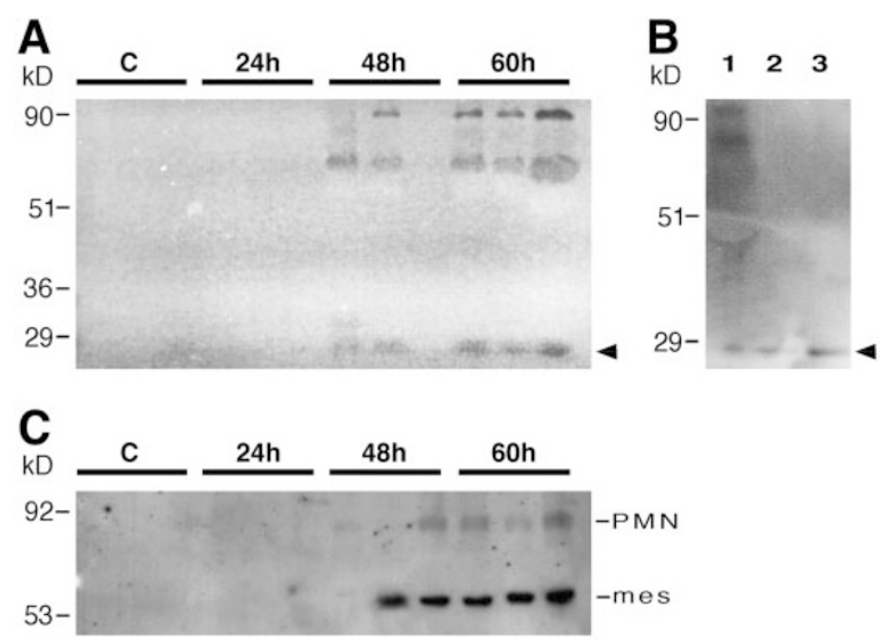

Figure 2. BALF samples from controls and rats exposed to $>95 \%$ oxygen for 24, 48, and $60 \mathrm{~h}$. Gelatin zymogram (A); ECL Western immunoblotting for trypsin $(B)$. Lane 1: BALF sample from rat exposed to hyperoxia for $60 \mathrm{~h}$, lane 2: rat pancreatic trypsin, lane 3: human tumor-associated trypsin-2. Arrowheads indicate $28 \mathrm{kD}$ trypsin. ECL Western immunoblotting for MMP-8 (C). Both neutrophil-derived (PMN) and mesenchymal cell-derived (mes) isoforms of MMP-8 are detected. Positions of molecular weight standards indicated by $\mathrm{kD}$.

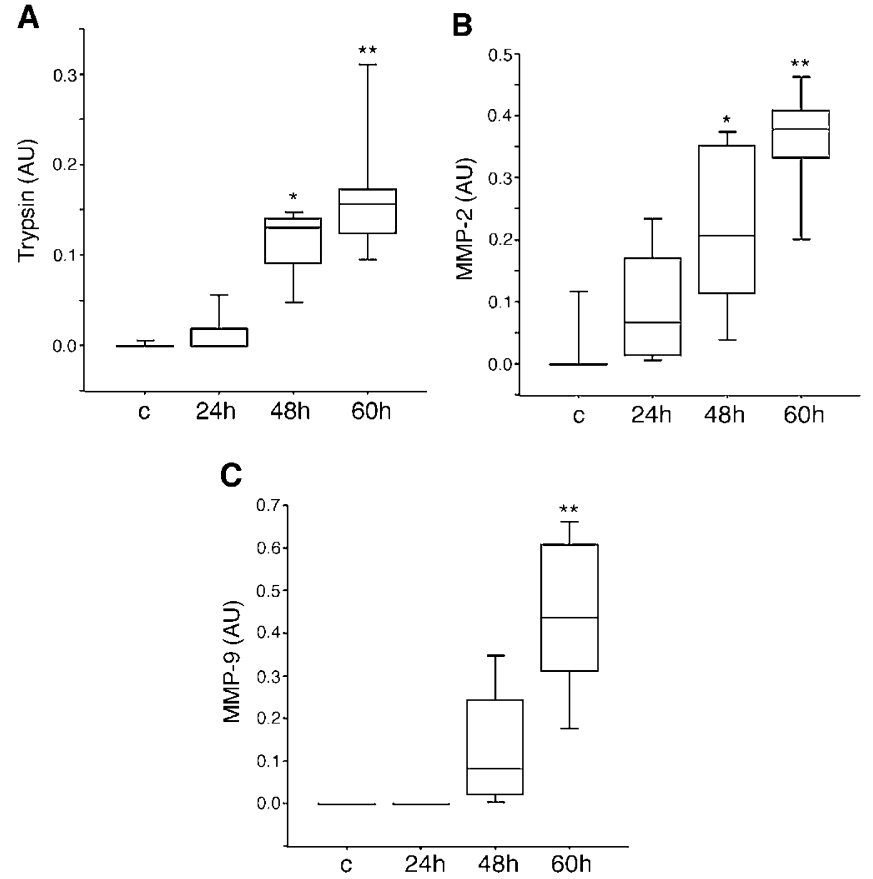

Figure 3. Levels of trypsin (A), MMP-2 (B), and MMP-9 $(C)$ in BALF from controls and rats exposed to $>95 \%$ oxygen for 24,48 , and $60 \mathrm{~h}$ as evaluated by densitometric analysis of gelatinolytic bands. Data shown as in Fig. 1. AU, arbitrary unit; ${ }^{*} p<0.01 ; * * p 0.0005 v s$ controls.
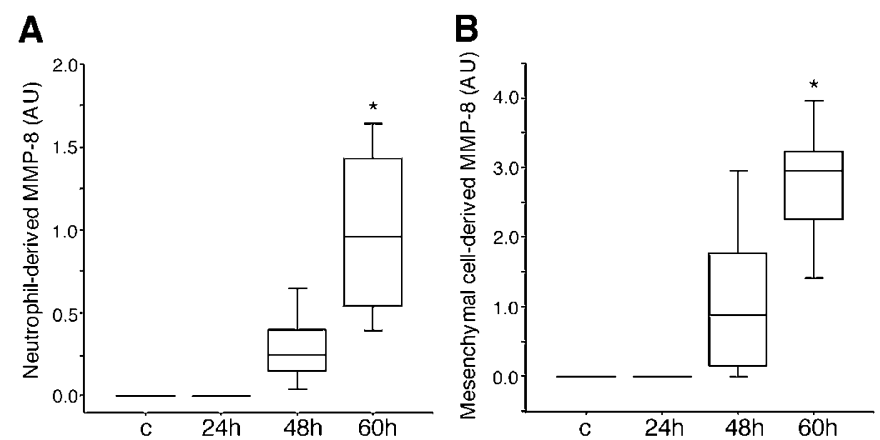

Figure 4. Levels of neutrophil-derived latent MMP-8 $(A)$ and mesenchymal cell-derived latent MMP-8 $(B)$ in BALF from controls and rats exposed to $>95 \%$ oxygen for 24,48 , and $60 \mathrm{~h}$. Evaluated by densitometric analysis of immunoreactive bands in Western immunoblots. Data shown as in Fig. 1. AU, arbitrary unit; $* p<0.0005$ vs controls.

(Fig. 6A). In four of the six rats exposed to 48 or $60 \mathrm{~h}$ of hyperoxia, moderate or strong trypsin immunoreactivity could be detected in vascular smooth muscle of large arteries, whereas smooth muscle of smaller arteries was negative. In addition, trypsin immunoreactivity was detected in hyaline membranes and occasionally in intra-alveolar macrophages.

MMP-8 immunohistochemistry. Almost no immunoreactivity for MMP- 8 could be demonstrated until $48 \mathrm{~h}$ of hyperoxia, when positive cells with a large cytoplasm obviously representing recruited macrophages could be detected in edematic perivascular space (Fig. 7A-C). At $60 \mathrm{~h}$, a large number of macrophages strongly positive for MMP-8 were detected in alveoli as well as in interstitium (Fig. $7 D$ and $E$ ). Although MMP- 8 was predominantly localized in macrophages, at $48 \mathrm{~h}$, positive immunostaining was also found in intravascular and 


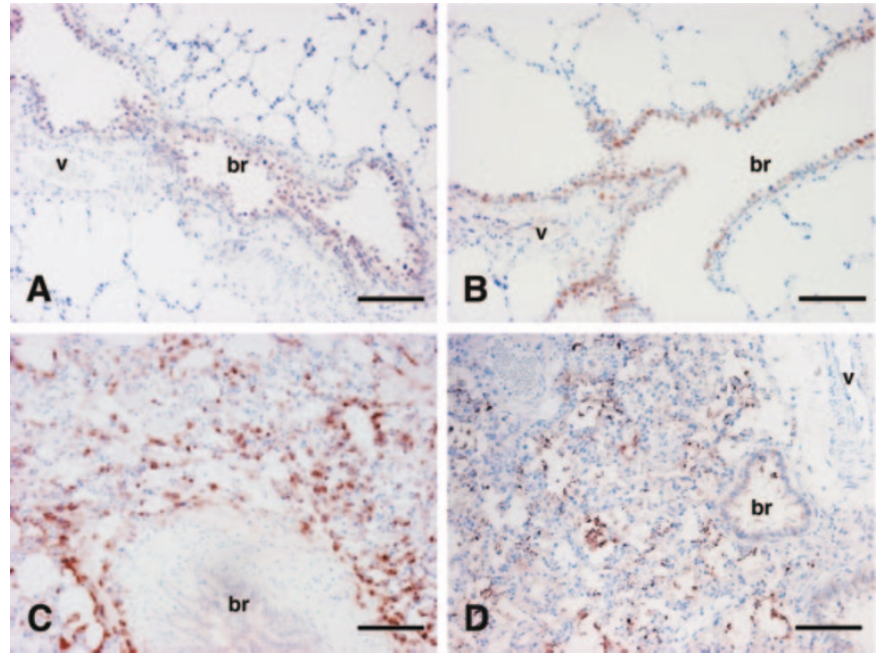

Figure 5. Immunohistochemical localization of trypsin in hyperoxia-injured and control rat lung. In controls $(A)$ and rats exposed to $>95 \%$ oxygen for $24 \mathrm{~h}(B)$, low trypsin immunoreactivity is observed in bronchial epithelium, whereas alveolar epithelium is predominantly negative. After exposure to $>95 \%$ oxygen for $48 \mathrm{~h}(C)$ and $60 \mathrm{~h}(D)$, strong trypsin immunoreactivity is detected in alveolar epithelium, whereas immunoreactivity in bronchial epithelium remains low. br, bronchiole; v, blood vessel. Scale bars $=100 \mu \mathrm{m}$.
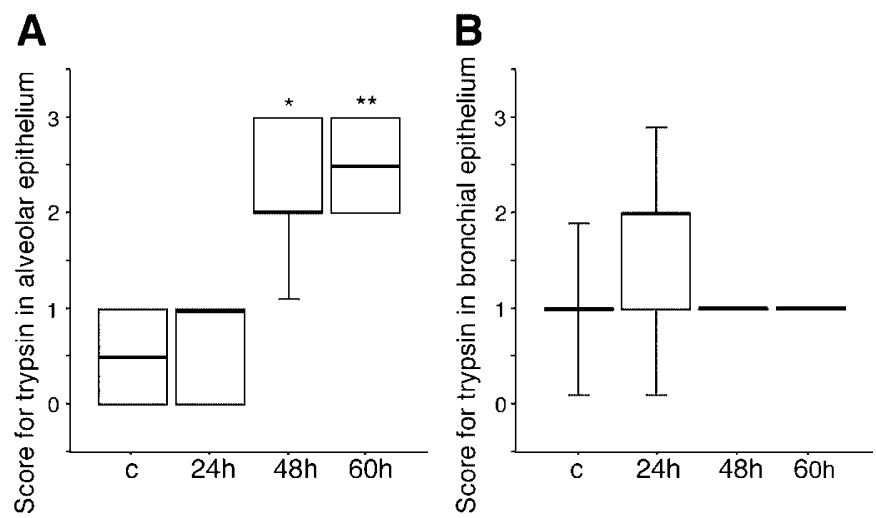

Figure 6. Box plot of semiquantitative analysis of trypsin immunoreactivity in alveolar $(A)$ and bronchial $(B)$ epithelium in normoxia controls and rats exposed to $>95 \%$ oxygen for 24,48 , and $60 \mathrm{~h}$ ( $n=6$ per group). Semiquantitative scoring of trypsin immunoreactivity was assessed as follows: absent $=$ 0 , low $=1$, moderate $=2$, or strong $=3$. Data shown as in Fig. $1 .{ }^{*} p<0.05$; **p $p<0.005$ vs controls.

perivascular neutrophils and, in addition, at $60 \mathrm{~h}$ in neutrophils located in the interstitium and intra-alveolar space (Fig. $7 F$ ).

\section{DISCUSSION}

Acute lung injury is marked by destruction of the alveolarcapillary barrier. We show a striking increase in the pulmonary expression of the potent matrix-degrading serine proteinase trypsin during the development of hyperoxic lung injury in rat. After $48 \mathrm{~h}$ of exposure to $>95 \%$ oxygen, immunohistochemical analysis demonstrated strong expression of trypsin in alveolar epithelium, which, in contrast, showed almost no immunoreactivity for trypsin under normoxic conditions.

Trypsin can directly attack various important structural components of the pulmonary ECM such as native collagen types I and IV $(3,25)$, of which collagen IV is the major

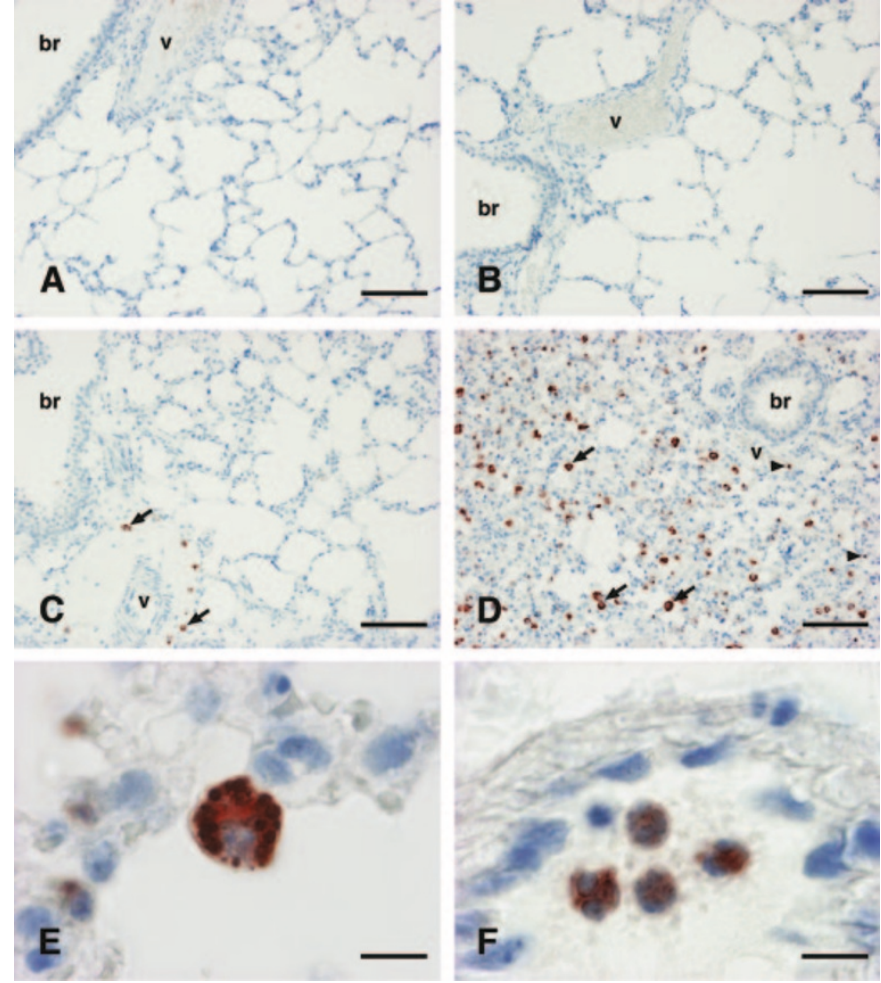

Figure 7. Immunohistochemical localization of MMP-8 in hyperoxia-injured and control rat lung. Lung samples from control $(A)$ and rat exposed to $>95 \%$ oxygen for $24 \mathrm{~h}(B)$ show no MMP-8 immunoreactivity. In rats exposed to $>95 \%$ oxygen for $48 \mathrm{~h}(C)$ and $60 \mathrm{~h}(D)$, marked MMP-8 immunoreactivity is detected in recruited macrophages (arrows) and neutrophils (arrowheads). (E) Positive intra-alveolar macrophage; $(F)$ positive intravascular neutrophils. br, bronchiole; v, blood vessel. Scale bars: $A-D=100 \mu \mathrm{m} ; E$ and $F=10 \mu \mathrm{m}$.

component of the alveolar-capillary BM. In addition to trypsin, zymography of BALF samples from rats exposed to 48 and $60 \mathrm{~h}$ of hyperoxia demonstrated the up-regulation of two other gelatinolytic enzymes that were identified as MMP-2 and -9. Similarly to trypsin, MMP-2, and MMP-9 can efficiently degrade BM structures $(2,13)$. The marked upregulation of trypsin, MMP-2, and MMP-9 in BALF coincided with an increase in the alveolar-capillary permeability, as indicated by increased protein concentration in BALF, suggesting that they may play a role in the degradation of alveolar-capillary BM associated with the development of hyperoxic lung injury. In accordance with our results, an earlier study showed increased expression of pulmonary MMP-2 and -9 in rats exposed to $100 \%$ oxygen for $60 \mathrm{~h} \mathrm{(26).}$ The expression of MMP-2 was localized in interstitial cells and MMP-9 in intra-alveolar macrophages (26). In our study, the markedly increased expression of trypsin in alveolar epithelium corroborates an important role for alveolar epithelium in the pathogenesis of oxidant injury leading to increased permeability and subsequent pulmonary edema $(19,20)$.

Trypsin efficiently activates various pro-MMPs, including MMP-8 and -9 , at very low concentrations by cleaving off the activation propeptide, which concomitantly results in diminished molecular weight of the target MMP $(2,3)$. In this study, most of the MMP-2, -8, and -9 detected in BALF samples were in nonconverted proforms as demonstrated by Western 
immunoblotting. This is in line with the findings of our previous study, in which we characterized the presence and the molecular weight forms of MMP-2, -8, and -9 in tracheal aspirate fluid samples from preterm infants with RDS (16). It is noteworthy that some of the nonconverted forms may represent oxidatively activated forms of these MMPs in vivo since oxidative activation of MMP- 8 or -9 does not necessarily involve changes in their molecular sizes $(27,28)$.

Besides its capacity to degrade ECM and BM structures, trypsin can cause tissue damage by inducing inflammation $(11,29,30)$. In a rat model of pancreatitis-associated lung injury, infusion of trypsin or trypsinogen causes an acute dose-dependent pulmonary injury characterized by perivascular edema and hemorrhage (29). This lung injury is neutrophil dependent and possibly mediated by the ability of trypsin to up-regulate pulmonary intercellular adhesion molecule-1, a key vascular endothelial adhesion molecule necessary for transport of leukocytes from intravascular space into inflamed tissues (30). The proinflammatory effects of trypsin may also be mediated through activation of $\mathrm{PAR}_{2}$, a G protein-coupled receptor that is believed to play an important role in inflammation $(10,11) . \mathrm{PAR}_{2}$ is markedly up-regulated by inflammatory agents and widely expressed in lungs (11). Activation of $\mathrm{PAR}_{2}$ increases lung vascular and epithelial permeability to protein and causes pulmonary edema in a dose-dependent manner (10). In preterm infants with RDS, trypsin-2 colocalizes with $\mathrm{PAR}_{2}$ in airway epithelium (12).

However, increased trypsin in alveolar epithelium may also play a protective role in the development of lung injury. In the injured lung, active transepithelial transport of $\mathrm{Na}^{+}$limits alveolar edema (31). Trypsin increases ion transport across rat alveolar type II cells and paracellular resistance, indicating that it may play an important role in the clearance of alveolar fluid (32). In fluid-filled lungs in a rat model, inhibition of trypsin by intratracheal soyabean trypsin inhibitor or $\alpha_{1}$ antitrypsin decreases amiloride-sensitive lung fluid clearance, and the effect is partially restored by instillation of trypsin (32).

In control rats, we detected low trypsin expression in bronchial epithelium. This is in accordance with earlier studies showing expression of trypsin in bronchial epithelium of human adults and of term newborn infants without pulmonary pathology and supports the hypothesis that trypsin also participates in normal cellular functions in the lung $(7,8)$.

We observed a marked up-regulation of MMP-8 after 48 of exposure to hyperoxia. MMP-8 (collagenase-2) was previously regarded solely as a neutrophil-specific MMP that is stored in granules and released on degranulation (33). However, certain activated mesenchymal cells and macrophages also express MMP-8 (18,23). In our study, immunoblotting of BALF samples demonstrated the presence of both neutrophilderived $80-\mathrm{kD}$ MMP-8 and 60-kD mesenchymal cell-derived MMP-8 species, of which the mesenchymal cell-derived MMP-8 species clearly predominated. Immunohistochemical analysis confirmed that in the hyperoxic lung, MMP-8 was mostly expressed in recruited macrophages, which at $48 \mathrm{~h}$ were detected in perivascular space and at $60 \mathrm{~h}$ in alveoli and interstitium. In inflammation, MMP-8 is believed to have a pivotal role in the degradation of collagen Type I. Recently, an unexpected anti-inflammatory role was evidenced for MMP-8 in the lung $(15,34)$. One possible mechanism is the regulation of inflammatory cell apoptosis, as demonstrated by reduced neutrophil apoptosis in MMP-8-/- mice during allergeninduced lung inflammation (34). During the development of hyperoxic lung injury, a large number of infiltrating inflammatory cells is found in the rat lung (35). Whether the role of MMP-8 in hyperoxic lung injury is anti-inflammatory possibly by regulating inflammatory cell apoptosis remains a subject for future research.

In summary, in a rat model of hyperoxic lung injury, we have demonstrated a striking increase in pulmonary expression of the potent matrix-degrading serine proteinase trypsin after $48 \mathrm{~h}$ of hyperoxia. Trypsin was localized in alveolar epithelium, which in controls was predominantly negative. In line with trypsin, the expression of especially mesenchymal cell-derived MMP-8 was clearly increased during the course of hyperoxic lung injury and was localized in intra-alveolar and interstitial macrophages. Although we cannot directly draw a parallel from our results in the hyperoxic lung injury model to earlier findings in preterm infants with RDS, these results support the hypothesis that high pulmonary levels of trypsin and MMP- 8 are injurious in the lung. Further exploration of the roles of trypsin and MMP- 8 in acute lung injury may offer new targets for therapeutic intervention.

Acknowledgments. We thank Marjatta Vallas, Päivi Peltokangas, and Elina Laitinen for excellent technical assistance.

\section{REFERENCES}

1. Maina JN, West JB 2005 Thin and strong! The bioengineering dilemma in the structural and functional design of the blood-gas barrier. Physiol Rev 85:811-844

2. Sorsa T, Salo T, Koivunen E, Tyynelä J, Konttinen YT, Bergmann U, Tuuttila A, Niemi E, Teronen O, Heikkilä P, Tschesche H, Leinonen J, Osman S, Stenman UH 1997 Activation of type IV procollagenases by human tumor-associated trypsin-2. J Biol Chem 272:21067-21074

3. Moilanen M, Sorsa T, Stenman M, Nyberg P, Lindy O, Vesterinen J, Paju A, Konttinen YT, Stenman UH, Salo T 2003 Tumor-associated trypsinogen-2 (trypsinogen-2) activates procollagenases (MMP-1, -8, -13) and stromelysin-1 (MMP-3) and degrades type I collagen. Biochemistry 42:5414-5420

4. Paju A, Stenman UH 2006 Biochemistry and clinical role of trypsinogens and pancreatic secretory trypsin inhibitor. Crit Rev Clin Lab Sci 43:103-142

5. Lutcke H, Rausch U, Vasiloudes P, Scheele GA, Kern HF 1989 A fourth trypsinogen (P23) in the rat pancreas induced by CCK. Nucleic Acids Res 17:6736

6. Stenman UH, Koivunen E, Vuento M 1988 Characterization of a tumor-associated serine protease. Biol Chem Hoppe Seyler 369:9-14

7. Cocks TM, Fong B, Chow JM, Anderson GP, Frauman AG, Goldie RG, Henry PJ, Carr MJ, Hamilton JR, Moffatt JD 1999 A protective role for protease-activated receptors in the airways. Nature 398:156-160

8. Cederqvist K, Haglund C, Heikkilä P, Sorsa T, Tervahartiala T, Stenman UH, Andersson S 2003 Pulmonary trypsin-2 in the development of bronchopulmonary dysplasia in preterm infants. Pediatrics 112:570-577

9. Towatari T, Ide M, Ohba K, Chiba Y, Murakami M, Shiota M, Kawachi M, Yamada H, Kido H 2002 Identification of ectopic anionic trypsin I in rat lungs potentiating pneumotropic virus infectivity and increased enzyme level after virus infection. Eur J Biochem 269:2613-2621

10. Su X, Camerer E, Hamilton JR, Coughlin SR, Matthay MA 2005 Protease-activated receptor-2 activation induces acute lung inflammation by neuropeptide-dependent mechanisms. J Immunol 175:2598-2605

11. Steinhoff M, Buddenkotte J, Shpacovitch V, Rattenholl A, Moormann C, Vergnolle N, Luger TA, Hollenberg MD 2005 Proteinase-activated receptors: transducers of proteinase-mediated signaling in inflammation and immune response. Endocr Rev 26:1-43

12. Cederqvist K, Haglund C, Heikkilä P, Hollenberg MD, Karikoski R, Andersson S 2005 High expression of pulmonary proteinase-activated receptor 2 in acute and chronic lung injury in preterm infants. Pediatr Res 57:831-836

13. Chakrabarti S, Patel KD 2005 Matrix metalloproteinase-2 (MMP-2) and MMP-9 in pulmonary pathology. Exp Lung Res 31:599-621 
14. Balbin M, Fueyo A, Tester AM, Pendas AM, Pitiot AS, Astudillo A, Overall CM, Shapiro SD, Lopez-Otin C 2003 Loss of collagenase-2 confers increased skin tumor susceptibility to male mice. Nat Genet 35:252-257

15. Owen CA, Hu Z, Lopez-Otin C, Shapiro SD 2004 Membrane-bound matrix metalloproteinase- 8 on activated polymorphonuclear cells is a potent, tissue inhibitor of metalloproteinase-resistant collagenase and serpinase. J Immunol 172:7791-7803

16. Cederqvist K, Sorsa T, Tervahartiala T, Maisi P, Reunanen K, Lassus P, Andersson S 2001 Matrix metalloproteinases-2, -8, and -9 and TIMP-2 in tracheal aspirates from preterm infants with respiratory distress. Pediatrics 108:686-692

17. Schock BC, Sweet DG, Ennis M, Warner JA, Young IS, Halliday HL 2001 Oxidative stress and increased type-IV collagenase levels in bronchoalveolar lavage fluid from newborn babies. Pediatr Res 50:29-33

18. Prikk K, Maisi P, Pirilä E, Reintam MA, Salo T, Sorsa T, Sepper R 2002 Airway obstruction correlates with collagenase-2 (MMP-8) expression and activation in bronchial asthma. Lab Invest 82:1535-1545

19. Crapo JD, Barry BE, Foscue HA, Shelburne J 1980 Structural and biochemical changes in rat lungs occurring during exposures to lethal and adaptive doses of oxygen. Am Rev Respir Dis 122:123-143

20. Royston BD, Webster NR, Nunn JF 1990 Time course of changes in lung permeability and edema in the rat exposed to 100\% oxygen. J Appl Physiol 69:1532-1537

21. Bradford MM 1976 A rapid and sensitive method for the quantitation of microgram quantities of protein utilizing the principle of protein-dye binding. Anal Biochem 72:248-254

22. Kinsella JP, Parker TA, Galan H, Sheridan BC, Halbower AC, Abman SH 1997 Effects of inhaled nitric oxide on pulmonary edema and lung neutrophil accumulation in severe experimental hyaline membrane disease. Pediatr Res 41:457-463

23. Hanemaaijer R, Sorsa T, Konttinen YT, Ding Y, Sutinen M, Visser H, van Hinsbergh VW, Helaakoski T, Kainulainen T, Ronka H, Tschesche H, Salo T 1997 Matrix metalloproteinase- 8 is expressed in rheumatoid synovial fibroblasts and endothelial cells. Regulation by tumor necrosis factor-alpha and doxycycline. J Biol Chem 272:31504-31509

24. Pirilä E, Ramamurthy N, Maisi P, McClain S, Kucine A, Wahlgren J, Golub L, Salo T, Sorsa T 2001 Wound healing in ovariectomized rats: effects of chemically modified tetracycline (CMT-8) and estrogen on matrix metalloproteinases $-8,-13$ and type I collagen expression. Curr Med Chem 8:281-294
25. Koshikawa N, Yasumitsu H, Umeda M, Miyazaki K 1992 Multiple secretion of matrix serine proteinases by human gastric carcinoma cell lines. Cancer Res 52:5046-5053

26. Pardo A, Selman M, Ridge K, Barrios R, Sznajder JI 1996 Increased expression of gelatinases and collagenase in rat lungs exposed to $100 \%$ oxygen. Am J Respir Crit Care Med 154:1067-1075

27. Saari H, Suomalainen K, Lindy O, Konttinen YT, Sorsa T 1990 Activation of latent human neutrophil collagenase by reactive oxygen species and serine proteases. Biochem Biophys Res Commun 171:979-987

28. Westerlund U, Ingman T, Lukinmaa PL, Salo T, Kjeldsen L, Borregaard N, Tjaderhane L, Konttinen YT, Sorsa T 1996 Human neutrophil gelatinase and associated lipocalin in adult and localized juvenile periodontitis. J Dent Res 75:1553-1563

29. Hartwig W, Werner J, Jimenez RE, Z'graggen K, Weimann J, Lewandrowski KB, Warshaw AL, Fernandez-del Castillo C 1999 Trypsin and activation of circulating trypsinogen contribute to pancreatitis-associated lung injury. Am J Physiol 277:G1008-G1016

30. Hartwig W, Werner J, Warshaw AL, Antoniu B, Castillo CF, Gebhard MM, Uhl W, Buchler MW 2004 Membrane-bound ICAM-1 is upregulated by trypsin and contributes to leukocyte migration in acute pancreatitis. Am J Physiol Gastrointest Liver Physiol 287:G1194-G1199

31. Yue G, Matalon S 1997 Mechanisms and sequelae of increased alveolar fluid clearance in hyperoxic rats. Am J Physiol 272:L407-L412

32. Swystun V, Chen L, Factor P, Siroky B, Bell PD, Matalon S 2005 Apical trypsin increases ion transport and resistance by a phospholipase $\mathrm{C}$-dependent rise of $\mathrm{Ca} 2+$ Am J Physiol Lung Cell Mol Physiol 288:L820-L830

33. Weiss SJ 1989 Tissue destruction by neutrophils. N Engl J Med 320:365-376

34. Gueders MM, Balbin M, Rocks N, Foidart JM, Gosset P, Louis R, Shapiro S, Lopez-Otin C, Noel A, Cataldo DD 2005 Matrix metalloproteinase-8 deficiency promotes granulocytic allergen-induced airway inflammation. J Immunol 175:25892597

35. Barry BE, Crapo JD 1985 Patterns of accumulation of platelets and neutrophils in rat lungs during exposure to $100 \%$ and $85 \%$ oxygen. Am Rev Respir Dis 132:548555 